\title{
Primary graft dysfunction after heart transplantation: a thorn amongst the roses
}

\author{
Sanjeet Singh Avtaar Singh ${ }^{1,2,3}$ (ID $\cdot$ Jonathan R. Dalzell ${ }^{2} \cdot$ Colin Berry $^{3} \cdot$ Nawwar Al-Attar $^{1,2,3}$
}

Published online: 25 April 2019

(C) The Author(s) 2019

\begin{abstract}
Primary graft dysfunction (PGD) remains the leading cause of early mortality post-heart transplantation. Despite improvements in mechanical circulatory support and critical care measures, the rate of PGD remains significant. A recent consensus statement by the International Society of Heart and Lung Transplantation (ISHLT) has formulated a definition for PGD. Five years on, we look at current concepts and future directions of PGD in the current era of transplantation.
\end{abstract}

Keywords Primary graft dysfunction $\cdot$ Pathophysiology $\cdot$ Treatment $\cdot$ Management $\cdot$ Prevention

\section{Primary graft dysfunction}

Heart transplantation remains the closest resemblance to a 'cure' for end-stage heart failure. Worldwide, more than 4000 adults undergo heart transplantation annually [1]. Whilst survival after cardiac transplantation has improved over the past four decades, primary graft dysfunction (PGD) is the leading cause of 30-day mortality post-transplant. The incidence of PGD is yet to be accurately delineated given the lack of an international consensus regarding its definition. Reports to date vary widely with respect to diagnostic criteria and definitions, therefore making incidence and outcomes difficult to compare between centres and regions. Prior to 2014, the International Society of Heart and Lung Transplantation (ISHLT) registry noted a 30-day of 10\% in all heart transplants done since 1982 [2]. The 90-day mortality was $14 \%$. Almost $70 \%$ of these deaths were coded as 'graft failure' or 'multiorgan failure' for which a large majority would likely constitute contemporary PGD. Here, we provide a comprehensive overview of PGD in heart transplantation.

Sanjeet Singh Avtaar Singh

sanjeetsingh@nhs.net

1 Department of Cardiothoracic Surgery, Golden Jubilee National Hospital, Glasgow, Scotland

2 Scottish National Advanced Heart Failure Service, Golden Jubilee National Hospital, Glasgow, Scotland

3 Institute of Cardiovascular \& Medical Sciences, University of Glasgow, Glasgow, Scotland

\section{Definition}

PGD presents as severe ventricular dysfunction of the donor graft which fails to meet the circulatory requirements of the recipient in the immediate post-transplant period. It may manifest as either single or biventricular dysfunction with low cardiac output and hypotension despite adequate filling pressures [3-5]. In 2014, Kobashigawa et al. provided a consensus definition and grading system based on the modified Delphi method [6]. This agreement upon a uniform definition allowed subsequent studies to outline its true incidence and further explore and identify the potential multifactorial aetiologies underpinning PGD.

PGD is defined as being a separate entity from secondary graft dysfunction, which is when a discernible cause for allograft dysfunction is identified. Such causes can include hyperacute rejection, graft dysfunction secondary to pulmonary hypertension or a recognised intraoperative complication. The diagnosis of PGD is made within $24 \mathrm{~h}$ post-transplantation and is separated into PGD-LV, for PGD affecting the left ventricle or biventricular failure; and PGD-RV for isolated right ventricular involvement [6]. A severity scale applies to PGD-LV. For the mild and moderate categories, it relies on the requirement of inotropic support with a composite score as described by Wernovsky et al. $(<10=$ mild, $\geq 10=$ moderate $)$ alongside either using echocardiography to identify ventricular dysfunction or right heart catheterisation to demonstrate haemodynamic compromise [7]. For the echocardiography criteria, the left ventricular ejection fraction $<40 \%$ is considered diagnostic for PGD (in the absence of secondary causes). With regard to 
haemodynamic parameters, high filling pressures i.e. a right atrial pressure (RAP) $>15 \mathrm{mmHg}$, and pulmonary capillary wedge pressure (PCWP) $>20 \mathrm{mmHg}$ indicate PGD if occurring in the context of a low cardiac index $(\mathrm{CI})\left(<2.0 \mathrm{~L} / \mathrm{min} / \mathrm{m}^{2}\right)$ lasting at least $1 \mathrm{~h}$. The requirement of an intra-aortic balloon pump signifies moderate PGD-LV, whereas requirement of extracorporeal short-term mechanical circulatory support in the form of extracorporeal membrane oxygenation (ECMO) or ventricular assist devices (VADs) in any form (percutaneous/ surgical) is diagnostic of severe PGD-LV [6].

PGD-RV does not have a severity scale and is diagnosed based on the requirement of a right-sided short-term VAD (RVAD) or right heart catheter measured haemodynamics in keeping with isolated right-sided dysfunction (RAP > $15 \mathrm{mmHg}$, PCWP $<15 \mathrm{mmHg}, \mathrm{CI}<2.0 \mathrm{~L} / \mathrm{min} / \mathrm{m}^{2}$, TPG $<$ $15 \mathrm{mmHg}$ and/or pulmonary artery systolic pressure < $50 \mathrm{mmHg}$ ) [6].

Previous studies had used the need for mechanical circulatory support as a criterion for diagnosis of primary graft dysfunction; however, the timing of initiation of therapy and endpoints differs from these studies, leading to significant variation in incidence reporting $(2.3-32.4 \%)$ [4, 8-11]. With an increasing trend towards utilisation of marginal donor organ due to increasing waiting list pressures, a resultant reduction in threshold for initiation of ECMO support in certain patients to support the graft in the initial phase of reperfusion (first $24 \mathrm{~h}$ ) may result in an over-estimation of the incidence of PGD [12]. This is especially true in high-risk recipients with a significant inflammatory milieu as a result of receiving a combination of in-hospital inotropic or short- or long-term mechanical circulatory support pre-transplant.

\section{Pathophysiology of PGD}

The donor heart is exposed to a multitude of physiological insults at four specific time points: brainstem death, hypothermic ischaemia, warm ischaemia and ischaemia-reperfusion injury.

\section{Brainstem death}

The first insult occurs during declaration of brainstem death in donation after brainstem death (DBD). Raised intracranial pressure (ICP) invariably is the final pathway in DBD donors in which case the aetiology of death is usually a result of an intracerebral haemorrhage, hypoxia leading to oedema, inflammation or a space occupying lesion in the cranium. The cerebral perfusion pressure is usually maintained by homeostatic mechanisms which result in an increased arterial pressure. Due to the limited plasticity of the brain within the confines of the cranium, brain herniation ensues resulting in pontine ischaemia [13]. This causes a surge in the adrenergic response, resulting in pulmonary and systemic hypertension which increases the afterload in both ventricles causing myocardial ischaemia. In some patients, stimulation of baroreceptors results in the classic Cushing's response characterised by hypertension and bradycardia $[14,15]$.

Vasomotor tone is reduced to the loss of spinal cord sympathetic activity resulting in unopposed vasodilatation, further reducing preload and indirectly afterload, affecting coronary blood flow and reducing myocardial perfusion. As a response, there is an intense release of myocardial noradrenaline immediately after brain death that results in mitochondrial and cytosolic calcium overload to increase contractility to counteract this unopposed vasodilatation [15]. Pituitary ischaemia may also occur during brain herniation resulting in significant endocrine derangement [16].

These patients are also prone to metabolic disturbances due to acidosis, hypomagnesaemia or hypokalemia secondary to mannitol initiation to reduce ICP, catecholamine administration, all of which contribute to increased myocardial oxygen demand or reduced myocardial perfusion [16]. This initial surge may also cause catecholamine depletion leading to a vicious circle of impaired myocardial oxygenation with increasing myocardial oxygen demand [13].

Early donor management may reduce the deleterious effects of the abovementioned phenomenon. Early administration of vasopressors is aimed at reducing the unopposed vasodilatation [17]. Methylprednisolone administration has been shown to reduce lung injury independently from its antiinflammatory activity in animal studies as well as reduce extravascular lung water and reduce PCWP in DBD donors [18, 19]. It is also used in conjunction with insulin to ensure normoglycemia in the donor [20]. The role of thyroid hormone replacement is uncertain during donor management with current consensus suggesting triiodothyroxine $\left(\mathrm{T}_{3}\right)$ administration only in depleted donors [16, 19, 21, 22].

\section{Hypothermic ischaemia}

Despite advancements in normothermic ex vivo perfusion devices, cold storage remains the mainstay of transportation after organ retrieval. Organ retrieval often has two distinct phases, a warm phase and a cold phase. The warm phase involves dissection of the heart and exposure of the innominate artery and the two cavae with variations in the degree of dissection depending on whether the lungs are to be retrieved as well. The retrieval surgeon also palpates the coronary arteries for potential disease. The aorta is prepared for administration of cold cardioplegia for commencement of the cold phase.

Depending on the size of the patient and type of cardioplegic solution administered, the volume of administration may differ. The retrieval surgeon then performs a left atriotomy by lifting the heart. Once the aortic cross-clamp is applied, cold cardioplegia is infused via the aortic root at approximately $4{ }^{\circ} \mathrm{C}$. The retrieval process is completed with the heart placed in a cold storage container. Cold storage induces hypothermic arrest of metabolism and maintains viability during this reduced 
metabolic state, therefore abating cellular swelling and minimalizing reperfusion injury [23]. At these temperatures, and with limited oxygenation, the heart switches from aerobic to anaerobic metabolism. This can have deleterious effects on the stored organs as ATP is slowly depleted; however, it should be noted that in the hypothermic state $\left(0-4{ }^{\circ} \mathrm{C}\right)$, there is a 12 fold decrease in metabolic rate [24]. The overall goal is to reduce the accumulation of mitochondrial byproducts of metabolism such as oxygen free radicals. Cold storage is also based on the assumption that there is no variation in temperature and the heart is uniformly cooled. In elderly patients whereby, pathologic LV hypertrophy may be noted especially in those with a clinical history of hypertension this may not be possible, possibly explaining why these hearts are more susceptible to ischaemic injury $[4,25]$. The length at which the hearts are kept in cold storage may also play a part in the formation of these free radicals. Cellular swelling and lactic acidosis occurs in prolonged cold storage, causing a rise in intracellular $\mathrm{H}^{+}$ions [26]. The $\mathrm{Na}^{+} / \mathrm{H}^{+}$exchanger is activated resulting in an increase in intracellular $\mathrm{Na}^{+}$which activates the $\mathrm{Na}^{+} / \mathrm{Ca}^{2+}$ exchanger $[27,28]$. The final pathway is the accumulation of cytosolic $\mathrm{Ca}^{2+}$. This will play a major role in the pathogenesis of ischaemic-reperfusion injury.

\section{Warm ischaemia}

On arrival at the recipient centre, the heart is removed from cold storage and inspected. The period in which the heart is removed from cold storage or from ex vivo normothermic perfusion to the final release of the recipient aortic crossclamp is termed warm ischaemic time. The heart is exposed to warmer temperatures which slowly increases its metabolic rate resulting in increased formation of oxygen free radicals. In a study by Marasco et al., warm ischaemic time and increasing donor age were independent predictors of early survival, suggesting an acceleration of the deleterious effects described during the cold ischaemic phase [29]. Similar findings were noted by Banner et al., despite a broader definition of warm ischaemic time termed surgical implant time (i.e. arrival of heart to theatre to release of recipient aortic cross-clamp).

\section{Ischaemia-reperfusion injury}

Ischaemia-reperfusion injury (IRI) is defined as cardiomyocyte damage secondary to myocardial restoration of blood flow [30]. On release of the recipient cross-clamp, the donor heart is reperfused which leads to further calcium overload. This alongside the release of oxygen free radicals activates the formation of mitochondrial permeability transition pores (MPTP) which are non-specific, thus allow free movement of apoptotic factors across the cell membrane [31]. This causes a cascade of myocardial damage, causing loss of cardiomyocyte function and viability; all of which are most pronounced immediately after reperfusion [32]. Post-conditioning may play a role in attenuating the effects of IRI by inhibiting MPTP formation. Cyclosporine A, a known MPTP desensitiser, has been shown to induce appreciable protection in acute myocardial infarction [33]. However, a recent meta-analysis failed to show any benefit of cyclosporine A post-infarction [34]. Other forms of preconditioning have also been suggested in an attempt to inhibit MPTP formation have shown some promise in animal studies [35-37]. However, larger clinical trials in surgical revascularisation studies have revealed mixed results with some studies showing clinical improvements [38] and others showing minor biochemical improvements with no clinical benefit [39-43]. The proponents of ischaemic preconditioning have suggested that the duration of ischaemia in these studies probably limits the effect of preconditioning with prolonged ischaemia showing greater benefit of preconditioning [44]. To date, no studies have been performed in human heart transplants, with animal models of orthotopic heart transplants showing promising results potentially highlighting its benefits in prolonged ischaemia [45].

Animal studies do however highlight attenuation of IRI using preconditioning in diabetics [46-48], females [49, 50], LV hypertrophied hearts [51], obesity [48], hypertensives [52] and in the elderly $[50,52,53]$; all of which have been noted to be risk factors for PGD.

Another mechanism of IRI is hypercontracture-mediated sarcolemmal rupture (HMSR). During the ischaemic phase, the low cytosolic ATP concentrations are quickly exhausted resulting in myofibrillar shortening that remains fixed as all cross-bridges between actin and myosin remain in an attached state [54]. This causes a moderate contracture with little structural damage but leads to cytoskeletal defects and increasing the cardiomyocyte fragility to mechanical damage which is reversible with early reperfusion [55].

Reperfusion-induced hypercontracture occurs after prolonged ischaemia. There is greater myofibrillar shortening and cytoskeletal damage when compared to the ischaemic phase alone. It causes a marked rise in end-diastolic pressure with increased ventricular wall stiffness. It is shown to be due to $\mathrm{Ca}^{2+}$ overload which develops during ischaemia and is rapidly re-energised, as it would on release of the crossclamp [56]. In cellular studies, re-perfused infarcts consist almost exclusively of contraction band necrosis [56]. Sarcolemmal rupture occurs due to the degradation of structural proteins like $\alpha$-fodrin [57] and ankyrin [58], impairing the $\mathrm{Na}^{+} / \mathrm{Ca}^{2+}$ exchanger pumps. Sarcolemmal rupture also results in increasing $\mathrm{Na}^{+}$influx into cardiomyocytes via gap junctions and may propagate to adjacent cells [59].

\section{Donation after circulatory death}

Donation after circulatory death (DCD) provides a different set of insults to the donor heart. The heart is placed in a 
hypoxemic and hypercarbic environment following withdrawal of life support [60]. This causes pulmonary vasculature constriction, with increased pulmonary vascular resistance imposed on the right heart [61]. Although the catecholamine surge of brainstem death is not present, the hypoxemic environment induces an adrenergic response. This quickly depletes the myocardial energy stores-leading to circulatory arrest. A mandatory standoff period ensues as part of the guidelines for declaration of circulatory death [62]. The heart is exposed to a period of warm ischaemic time that is present until the institution of either normothermic regional perfusion (NRP) or ex vivo normothermic perfusion using the Organ Care System device (TransMedics Organ Care System (OCS), Andover, MA, USA) [63].

This prolonged ischaemic period causes intracellular acidosis which causes activation of the $\mathrm{Na}^{+} / \mathrm{H}^{+}$exchanger in a pathway similar to the warm ischaemic period described above, with a net result of an accumulation of intracellular $\mathrm{Ca}^{2+}$ and follows the ischaemic-reperfusion pathway on reperfusion.

\section{Recipient factors}

Some recipient factors may also predispose a patient to PGD. Recipients, especially patients who have been on inotropic support and mechanical devices, have activation of their systemic inflammatory response, which causes intense vasodilation and therefore lowering of the systemic vascular resistance. The net result is a hypotensive state despite adequate filling and a high cardiac output that is refractory to vasopressor support [64]. The exact pathogenesis of this is poorly understood to date, some mechanisms have been postulated. Vasodilation is believed to be caused by the unopposed activation of vascular smooth muscle adenosine triphosphatesensitive potassium channels ( $\mathrm{K}_{\mathrm{ATP}}$ channels). Endogenous nitric oxide, a potent vasodilator, is also implicated in the pathogenesis alongside vasopressin deficiency [65].

Prolonged ischaemic time has been shown in previous studies to correlate with complications occurring after cardiopulmonary bypass [64]. This association is thought to be due to the summative effect of the exposure of blood to synthetic surfaces of the cardiopulmonary bypass circuit which potentiates a cascading inflammatory response. This in turn could explain the increased incidence in recipients on advanced mechanical circulatory support (ECMO or Short-Term VAD). The ischaemic time may also be prolonged in some patients whereby careful dissection is necessitated following a previous sternotomy, highlighting the importance of communication with the retrieval team to potentially delay the retrieval procedure to minimise ischaemic time [66].

Another pathogenic mechanism that has been suggested in the past is recipient pulmonary hypertension. The donor heart in its ischaemic state is exposed to a relatively high pulmonary vascular resistance, giving rise to right-sided heart failure. Due to the poor adaptability of the right ventricle to a sudden change in vascular resistance, biventricular dysfunction ensues due to a reduced left-sided preload, thereby reducing coronary perfusion and end organ perfusion in the systemic circulation [67]. This however is currently termed secondary graft dysfunction and is beyond the scope of this review.

\section{Risk factors for PGD}

There are several risk factors that have been suggested that may contribute to PGD. These include donor factors, recipient factors and procedural factors.

\section{Donor factors}

Donor age Avtaar Singh et al. (2018) highlighted donor age to be a significant risk factor on multivariate analysis. This may have been due to the poorer tolerance for long ischaemic times in hearts from older donors. They highlighted an odds risk of $20 \%$ for each decade increment in donor age. A similar finding was noted by Russo and colleagues [68]. They noted that in younger donors, there was not significant correlation between ischaemic time and survival. However, as the donor age increased, there was a statistically significant correlation between ischaemic times and survival in donor ages $>20$. Other studies have also shown a direct correlation between donor age and low cardiac output states post-operatively, which were likely PGD, however were not characterised as such due to the lack of a definition at the time of publication [69-72].

Gender mismatch Female-donor to male-recipient gender mismatch is a risk factor for PGD. The exact mechanism is poorly understood as this persisted despite organ size matching. Maledonor to female-recipients did not result in an increased PGD rate. Gender-mismatched organs also had a poorer survival at up to 5 years. In liver transplantation, recipients had poorer graft survival in female-donor/male-recipient cohorts compared with other donor-recipient gender groups despite adjustment for donor risk factors and recipient variables [73]. The role of H-Y minor histocompatibility antigens has been implicated. Several haemotopoetic stem cell studies have shown an increased relapse rate in patients undergoing stem cell transplants in femaledonor/male-recipient cohorts [74, 75].

Cause of death in the donor Intracranial haemorrhage is the most common cause of death for DBD donors in the UK. One study showed increased PGD rates in organs retrieved from donors with intracranial haemorrhage compared to donors with traumatic cause of death [76]. The exact mechanism is not clear, although it is thought to be due to a prolonged exposure to the catecholamine surge [76]. Animal studies have shown a direct correlation between increased intracranial pressure and worsening myocardial function [15, 77]. Avtaar 
Singh et al. highlighted intracranial haemorrhage as a risk factor on the unadjusted analysis although it was not present during multivariate analysis. Another study showed an association with early mortality with a lower survival to discharge rate in patients transplanted with hearts from donors with atraumatic intracranial haemorrhage [78].

Donor left ventricular hypertrophy Donors with hypertension often have a degree of left ventricular hypertrophy (LVH). This is more apparent across Europe where the average age of the donor is older compared to North America [1]. The use of donors with LVH has resulted in mixed results with some centres having favourable results [25, 79-82] but others reporting an increased incidence of early graft failure or poorer survival [83-85]. The reason for the varying results is likely due to the association of LVH to age, which is an independent predictor of PGD. Hypertrophied hearts with associated hypertension are more susceptible to ischaemic injury [86]. Therefore, the ischaemic time for donors with hypertrophied hearts should be kept to a minimum. The Harefield team reported their experience in using marginal donors with mild LVH with normothermic ex vivo perfusion [87]. They showed promising short-term outcomes when utilising marginal hearts with continuous normothermic perfusion using the OCS device. The ISHLT guidelines also cites level of evidence $\mathrm{C}$ for a class IIa recommendation stating that "it would seem appropriate to use hearts from donors with LVH and LV wall thickness $<14 \mathrm{~mm}$ provided that it is not associated with ECG findings of LVH" [88].

Donor inotropic requirement Inotropic support is sometimes needed during the donor organ retrieval process due to the depletion of catecholamine and/or a systemic inflammatory phenomenon as described above. Noradrenaline use can cause left ventricular dysfunction in the absence of brain death [89]. It also has a dose-dependent detrimental effect on the right ventricle in DBD donors [90-92]. The use of vasopressin and terlipressin is currently recommended as first-line treatment to reduce the noradrenaline requirement [93]. It treats two conditions which occur commonly in DBD donors, neurogenic diabetes insipidus and reduction in systemic vascular resistance [94]. Venkateswaran et al. showed that vasopressin use could result in the elimination or reduction of noradrenaline use in more than $50 \%$ of donors [95].

\section{Recipient factors}

Pre-operative mechanical circulatory support Pre-operative recipient ECMO/VAD usage has also been linked to PGD post-operatively [4, 90, 96, 97]. Several factors have been suggested as potential causes which have been discussed under the pathophysiology section above.
A recent study by Truby and colleagues highlighted the role of continuous flow LVAD (CF-LVAD) in recipients as a risk factor for severe PGD [98]. This is of particular interest as CF-LVADs have contributed significantly to the growth and success of mechanical circulatory support for advanced heart failure for BTT and as destination therapy. CF-LVADs also account for more $95 \%$ of VAD implants currently [99]. Forty-five out of $56(80.4 \%)$ patients with severe PGD were bridged to transplant (BTT) using CF-LVADs in Truby's study [98]. It should be noted however there were significant other contributary factors as the severe PGD patients were older, had a higher percentage of previous amiodarone exposure, had higher creatinine levels, spent longer time on the waiting list and had a higher CVP/PCWP ratio which is possibly indicative of subclinical right ventricular dysfunction.

\section{Recipient diabetes mellitus}

The role of recipient diabetes as a predictor of PGD is evident in multiple studies [92]. The results of Avtaar Singh et al. however show that the $95 \%$ confidence interval $(0.9993-$ 4.1720) crosses the boundary of no effect for diabetes. Segovia's study was unable to account for recipient diabetes as a predictor of PGD when using robust statistical analysis (overfitting of regression models [100]. However, recipient diabetes seems to be a predictor of graft loss within and beyond the first-year post-transplant [101]. This may be due to direct glucose-mediated endothelial damage, oxidative stress from superoxide overproduction and production of advanced glycation end-products, which may result in changes in endothelial permeability, excessive vascular protein deposition and altered blood flow. Taghavi et al. revealed diabetic recipients were older and would more likely receive organs from diabetic donors who were who themselves were more often females and older [102].

Recipient age Several studies have associated advancing recipient age with PGD and mortality [90, 92]. A risk prediction model assessing in-hospital mortality for post-heart transplant patients included recipient age but utilised it as a categorical variable. The c-statistic of less than 0.7 however suggested poor performance [103]. ISHLT registry data also highlighted advancing recipient age with having slightly higher long-term mortality. This may probably reflect the higher incidence of comorbidities such as hypertension and diabetes in this cohort of patients as well [104]. Some studies have attributed this to the increased fatal infection rate in the elderly $[105,106]$.

Recipient re-sternotomy A recipient re-sternotomy indicates previous surgery, most commonly for durable ventricular assist device implantation, previous congenital cardiac surgery or previous coronary bypass or valvular surgery [107]. The dissection process in recipient who has undergone a previous 
sternotomy often is more complex and hazardous with the potential for significant injury [108]. Recipient resternotomy has been linked to an increased risk of severe PGD in a recent study. A similar study showed that patients with prior sternotomies had an almost threefold increase for PGD risk [109]. The increased technical difficulty of the surgery may result in longer ischaemic times and is associated with higher rates of blood transfusion and subsequent need for reoperation for bleeding [109-111]. Patients with prior sternotomies were also more likely be older [109] and have spent longer time on the waiting list [109], possibly indicating durable VAD implantation [110] in these patients as a bridge to candidacy/transplantation.

Recipient pre-operative amiodarone therapy Amiodarone is a class III antiarrhythmic used for a variety of arrhythmias including both ventricular, supraventricular and atrial tachyarrhythmias. Its mechanism of action is primarily by prolonging the refractory period myocardium. Arrhythmias are highly prevalent in advanced heart failure patients [112]. The evidence regarding PGD and the use of amiodarone in recipients appears to be conflicting. Studies have shown that patients who had received amiodarone before transplantation had significantly lower heart rates post-transplantation [113, 114], required atrial pacing for a longer time after transplantation [113] but had no increased inotropic requirements [113] and no increased mortality post-operatively [113-115]. Other studies have indicated a dose-dependent [116] or durationdependent [117] link between amiodarone use and PGD post-transplant.

\section{Procedural factors}

Ischaemic time In DBD donations, the ischaemic time consists of the placement of the donor aortic cross-clamp till the release of the recipient aortic cross-clamp [118]. For DCD donations, the ischaemic time is possibly underestimated with a period of functional warm ischaemia (starting when systolic blood pressure is less than $50 \mathrm{mmHg}$ ) till the heart is re-perfused on an ex vivo perfusion device (OCS) [63]. A second period of ischaemia ensues from removal of the heart from the OCS till release of the aortic cross-clamp from the recipient.

Cold ischaemic time consists of the time spent in cold storage and warm ischaemia ensues once the heart is removed from cold storage or the OCS rig till release of the aortic crossclamp. Prolonged ischaemic time is associated with an increased rate of PGD [4, 29, 92, 119]. Banner et al. noted that longer ischaemia time was a risk factor for 30-day mortality after heart transplantation. They also noted that the surgical implant time (i.e. warm ischaemic time) was an independent risk factor for 30-day mortality [120]. Avtaar Singh et al. noted that warm ischaemic time/implant time to be a significant independent predictor of ISHLT defined PGD. The direct ischaemic insult of warm ischaemia is explained in the pathophysiology above. Marasco et al. also noted found that poorer survival with a warm ischaemia time (WIT) of $>$ $80 \mathrm{~min}$ [29]. Ischaemic time is also closely related to donor age. Older donor organs are more susceptible to ischaemic injury compared to younger donor organs $[68,121]$.

Cardiopulmonary bypass time Prolonged cardiopulmonary bypass $(\mathrm{CPB})$ duration independently predicts post-operative morbidity and mortality after general cardiac surgery [122]. Kirklin and colleagues alluded to a systemic inflammatory response following CPB [123]. The mechanism of injury from $\mathrm{CPB}$ and ischaemic-reperfusion of the myocardium is similar, both producing a hyperdynamic circulatory state due to a low systemic vascular resistance, platelet and coagulation factor dysfunction, inflammatory pathway activation triggered by leucocytes and endothelial cells and finally cytokine release and formation of oxygen free radicals [124]. It is also linked to an increased blood product requirement which is associated with both infection and ischaemic post-operative morbidity, increased hospital stay, increased early and late mortality and increased hospital costs [125-127]. Therefore, prolonged CPB time may contribute to the worsening of the ischaemic injury caused by PGD.

Size mismatch The size of the donor graft has many implications on the recipient. It is a powerful predictor of survival recipients receiving undersized grafts having an increased 1year mortality, and a $36 \%$ increased mortality within the first 30 days [128]. Smits showed inferior survival in donors who were undersized by more than $20 \%$ using data from the Eurotransplant database [129]. This study however also showed an inferior survival amongst gender-mismatched donors, which were more likely to be undersized in female donors to male recipients. Patel et al. refuted the findings in an analysis of the UNOS database, suggesting increased pulmonary resistance as a confounder [130]. Another analysis of the UNOS database several years later concluded that donor/recipient BMI ratio $<0.75$ was associated with increase in post-transplant mortality in univariate analysis but not in multivariate analysis, highlighting gender mismatch as a confounder [131]. Other multi-institutional studies have also highlighted donor-recipient weight difference to be significant, but only in older grafts which were gender mismatched [132]. Jayarajan and colleagues noted that donor weight mismatching by up to $40 \%$ had no bearing on outcome in non-gender mismatched patients [133]. The significance of size mismatching is hard to elucidate from studies but smaller single-centre data suggests poorer outcomes such as an increased length of stay [134] and increased LV hypertrophy [135]. The direct link between PGD and size mismatch however remains elusive. 


\section{Investigations and biomarkers}

The current definition for PGD is based on the treatment options utilised. Several biomarkers have been suggested as potential predictors of PGD, although to date none are used in routine care.

\section{Inflammatory markers}

The pro-inflammatory state accompanying PGD supports the use of inflammatory markers as potential predictive biomarkers. Tumour necrosis factor- $\alpha$ (TNF- $\alpha$ ), interleukin-6 (IL-6), neutrophils and procalcitonin (PCT) have all been suggested as potential biomarkers.

TNF- $\alpha$ Tumour necrosis factors are produced by lymphocytes and macrophages that cause cell lysis [136]. TNF- $\alpha$ has been implicated in the pathogenesis of numerous inflammatory conditions including arthritis [137], asthma, chronic obstructive pulmonary disease (COPD), acute respiratory distress syndrome (ARDS) [138], myocarditis [139] and congestive heart failure [140].

Birks and colleagues noted an increased expression of TNF- $\alpha$ in unused donor hearts due to poor function and compared them with donors with good ventricular function (used donors) and patients with advanced heart failure (HF) [141]. In lung transplantation, a recent study highlighted the role of intravascular donor monocytes in the pathophysiology of IRI and PGD in lungs [142]. Another group showed reduction in PGD rates post-lung transplantation after leukocyte depletion [143]. Venkateswaran et al. highlighted poorer biventricular function in donors with elevated levels of TNF- $\alpha$ using serum immunoassays [144].

A Brazilian group showed recipients receiving grafts from donors expressing lower concentrations of plasma soluble tumour necrosis factor receptors 2 (sTNFR2) and IL-6, required more inotropic support post-transplantation [145].

IL-6 Interleukin 6 (IL-6) is produced in response to infections and tissue injuries by stimulation of acute phase responses. It bridges the adaptive and innate immune responses and plays a major role in autoimmune conditions [146, 147]. Birks et al. noted IL-6 mRNA expression was 2.4-fold higher in the unused donor hearts than in those used for transplantation, with levels almost five times higher than in the potential recipients with advanced heart failure [141]. The used donor hearts had an almost twofold increase of IL-6 mRNA levels compared to the recipients. These findings were also noted by Plenz and colleagues, who noted a significant rise in IL-6 and IL-6 receptors in DBD donors, comparable to patients with advanced heart failure in comparison with a control group not compromised by the sequelae of brain death. This may explain the close association of elevated IL- 6 serum levels and acute allograft dysfunction in the early post-operative period [148].

IL-6 was also shown to be associated with PGD post-lung transplantation. The serum and bronchioalveolar lavage concentrations of IL- 6 were higher in transplant recipients with PGD than those without [149].

Animal models have shown that ischaemic cardiac myocytes in watershed viable zones of a myocardial infarction exhibited reperfusion-dependent expression of IL-6 mRNA after reperfusion $[150,151]$.

Procalcitonin Procalcitonin (PCT) is a 116-amino acid peptide that has an approximate molecular weight of $14.5 \mathrm{kDa}$ and belongs to the calcitonin (CT) superfamily of peptides [152]. It is a biomarker that exhibits greater specificity than other proinflammatory markers in identifying patients with sepsis [152].

In transplantation, $\mathrm{PCT}$ was used to differentiate bacterial infection from organ rejection. PCT levels are elevated in both conditions but significantly higher in the presence of infections $[153,154]$. It has important prognostication value in heart transplantation with low levels signifying an uneventful course, and higher value indicating an increased mortality in the early post-operative period [155]. Venkateswaran et al. noted that elevated donor serum PCT levels were associated with poorer donor cardiac index and worse biventricular function despite early donor management during pre-retrieval optimisation [144]. The authors demonstrated that preoptimisation baseline PCT levels of less than or equal to $2 \mathrm{ng} \mathrm{mL} \mathrm{m}^{-1}$ was a potentially useful tool in predicting the end-management heart usability for transplantation. Similar findings were noted by Wagner and colleagues with increased 30-day mortality and early graft dysfunction in hearts utilised from donors with elevated PCT levels [156]. The increased early graft failure rate was also noted in renal [157], but not in liver [158] or lung transplantation [159].

Neutrophil to lymphocyte ratio Both NLR and platelet to lymphocyte ratio (PLR) have been used as markers of inflammation with prognostic value in coronary artery disease [160, 161] and other conditions. Neutrophil to lymphocyte ratios (NLR) have been shown to be independently related to mortality in patients hospitalised for acute heart failure with LVSD [162]. Implantation of LVAD in patients with heart failure showed reversibility of NLR which reflects the reversal of various HF-mediated inflammatory processes [163].

A group in Argentina studied the relationship between the two ratios and survival after heart transplantation [164]. They noted NLR (baseline and at $6 \mathrm{~h}$ ) to be a good predictor of early mortality post-heart transplantation but not PLR. The number of patients in the single-centre study was relatively small $(n=$ 111). A Polish single-centre study noted similar findings in their renal transplant cohort, with NLR showing good predictive value of early graft dysfunction [165]. Another recent 
study showed good correlation between NLR and survival after ECMO institution in non-transplant patients presenting with cardiogenic shock [166]. However, patients in the increased NLR ratio arm of this study were also significantly older with a higher blood urea nitrogen levels.

\section{Troponin}

Cardiac troponins are regulatory proteins that control the calcium-mediated interaction between actin and myosin. The measurements of serum cardiac troponin I (cTnI) and cardiac troponin $\mathrm{T}(\mathrm{cTnT})$ have shown to be sensitive and specific markers of myocardial damage [167].

The pathophysiology of brainstem death results in a catecholamine storm that is believed to cause transient myocardial ischaemia and injury [168]. Circulating cardiac troponin concentrations may therefore be elevated in the donor.

Several studies however have shown that elevated serum troponin levels in donors may predict adverse outcomes posttransplantation. Increasing cTnT levels have been shown to be associated with a reduction in left ventricular ejection fraction in the donor [169]. Potapov et al. showed in a single-centre observational study that increased donor cTnT levels were associated with an increased rate of early allograft failure [170]. They showed a similar association with PCT indicating a coexistent pro-inflammatory state in these donors. PCT and $\mathrm{cTnT}$ levels however showed poor specificity. There was also no correlation between PCT and $\mathrm{cTnT}$ values and there was no significant interaction between the two markers using a logistic regression model $(P=0.28)$. Vijay et al. conducted a similar study, using endomyocardial biopsy proven rejection at 1 year as the primary endpoint. They noted a linear correlation between grade of rejection at 1-year and donor cTnT levels [171]. Another study by Potapov et al. showed an association between increasing cTnI levels in donors to early graft dysfunction post-transplantation [172].

In donors with subarachnoid haemorrhages, cTnI was a good indicator for left ventricular dysfunction, however this was reversible, and did not affect outcomes post-transplant $[173,174]$. Boccheciampe et al. noted that cTnI values in donors were not associated with PGD or post-transplant survival [175]. Other larger studies of donor serum troponin have shown no association between elevated levels and PGD [176, 177].

A recent study of $\mathrm{cTnI}$ in the preservation solution (University of Wisconsin solution and Custodiol) during transportation of heart grafts however showed that elevated cTnI (scaled to the corresponding LV mass) was predictive of post-transplant PGD [178]. They also noted there was poor correlation between preservation fluid cTnI levels and donor serum cTnI levels. They raised the possibility that incomplete myocardial preservation may play a role in PGD pathogenesis. However, there were only 43 patients in the study, and only ischaemic time was noted to be a predictor of PGD in their logistic regression model.

\section{Brain natriuretic peptide/ $\mathrm{N}$-terminal pro-B-type natriuretic peptide}

Brain natriuretic peptide (BNP) and its amino-terminal profragment, N-terminal pro-B-type natriuretic peptide (NTproBNP) are commonly used for diagnosis and prognostication in heart failure $[179,180]$. They are released by the myocardium in response to increasing ventricular wall stress [181]. They have been shown to correlate well with ventricular dilation [181], adverse remodelling [182] and death after acute myocardial infarction [183]. Dronavalli et al. showed that elevated NT-proBNP correlate well to poor echocardiographic and haemodynamic findings of cardiac function in potential DBD donors [184]. Vorlat et al. linked increased BNP levels to a lower cardiac output post-transplant and a prolonged hospital stay [185]. They noted that a donor serum BNP of $>$ $160 \mathrm{pg} / \mathrm{mL}$ had $89 \%$ accuracy to predict poor cardiac performance in the recipient (cardiac index $<2.2 \mathrm{~L} / \mathrm{min} / \mathrm{m}^{2}$ ). The authors however could not show a correlation between postoperative inotropic support and BNP levels.

\section{Others}

SWItch/sucrose non-fermentable, a matrix-associated, actindependent regulator of chromatin subfamily a-like $1 \mathrm{SWItch} /$ sucrose non-fermentable, a matrix-associated, actindependent regulator of chromatin subfamily a-like 1 (SMARCAL1) is an intracellular protein that acts as a DNAdependent ATPase involved in transcription, DNA repair and chromatin dynamics [168]. Aharinejad et al. noted that elevated serum SMARCAL1 levels in their cohort of 336 donors were predictive of recipient PGD [186]. In addition, SMARCAL1 levels correlated well with survival at 3 months, 1 -year and 5-year survival. Using a donor serum cutoff of $\geq$ $1.25 \mathrm{ng} / \mathrm{mL}$, they demonstrated a $96 \%$ sensitivity and $88 \%$ specificity for predicting PGD. Pre-and post-aortic donor cross-clamp serum SMARCAL1 concentrations were the best markers of PGD risk. To date, no other validation studies have been performed.

Donor myocardial hypoxia-inducible factor-1a Hypoxia-inducible factor (HIF)-1 is a heterodimeric $\alpha, \beta$ transcription factor that mediates tissue responses to hypoxia [187]. Aharinejad et al. performed a series of assays using 857 donor LV myocardial biopsies obtained before and after aortic crossclamping in the donor, and at 10, 30 and 60 min following reperfusion [188]. In the cDNA array, only HIF- $1 \alpha$ mRNA expression after aortic cross-clamping in donors and at $10 \mathrm{~min}$ following the release of the aortic cross-clamp in the recipient were significant predictors of PGD. The authors hypothesise 
that the release of cytokines and inflammatory chemokines activated by ischaemia and reperfusion injury reach the highest peaks prior to cross-clamping and just after reperfusion. Other studies have demonstrated the protective signalling of HIF-1 against ischaemia-reperfusion injury in the heart $[189,190]$. To date however, there have been no further studies linked HIF-1 $\alpha$ to PGD.

Serum exosome proteomics Several published abstracts have highlighted the role of serum exosome proteomic analysis in the recipient as a potential biomarkers for PGD [191, 192]. Giangreco et al. noted that pretransplant serum exosome analysis revealed an inflammatory phenotype and complement activation in patients who later developed PGD which could be identified by the absence or presence of the biomarkers alone. Fine et al. showed this could be further used to differentiate patients who would later develop PGD-RV from PGD-LV. In their study, significant upregulation of angiotensinogen (AGT) and adiponectin (ADIPOQ) signalling pathways were noted in the PGD-LV group whereas hepatic growth factor activator (HGFAC) and insulin-like growth factorbinding protein 3 (IGFBP3) pathways were both upregulated in the PGD-RV group. The significance of these findings may hopefully shed light into the pathogenesis of PGD in the near future.

\section{Prevention of PGD}

A single administration of cold flush preservation fluid remains the gold standard for myocardial protection during transplantation. It confers reliable protection for a limited amount of ischaemic time in young donor hearts [6]. The increasing use of extended criteria donors however necessitate more aggressive protection strategies to attenuate the ischaemic effects on hearts. In a study conducted by the Hamburg group, they noted that the use of a leukocyte depleting filter alongside additional regular antegrade administration of Buckberg cold blood cardioplegia in intervals of 20 min resulted in a reduction of PGD rates [193]. Similar findings were noted by a group from the Czech Republic, utilising continuous cold blood cardioplegia followed by controlled reperfusion of warm blood [194]. The Glasgow group utilised a similar variation with continuous antegrade perfusion in a contemporary cohort of patients, resulting in a significant reduction in PGD rates compared to a historical group of patients and the national UK cohort [195]. The exact mechanisms by which additional cardioplegia administration reduces PGD remain uncertain. It may play a role in pre-conditioning, mitigating the impact of reperfusion or preventing generation and propagation of inflammatory pathways [196].

\section{Treatment and management of PGD}

Treatment of PGD thus far is still primarily supportive care. In a consensus statement by Kobashigawa et al., the treatment and management of PGD across five high volume transplant centres were evaluated. PGD is initially managed by using inotropic support using catecholamines and phosphodiesterase inhibitors. The most common escalation therapy follow inotropic use is using an intra-aortic balloon pump. Following this, advanced mechanical support is initiated which is usually directed by the expertise of the transplant units themselves. The most common mode of support is extracorporeal membranous oxygenation with both central and peripheral cannulation strategies utilised. The heart should be allowed to eject to prevent stasis and thromboembolic complications.

For primary RV-PGD, nitric oxide may be used to reduce the pulmonary vascular resistance. Following a period of support on ECMO, a short-term ventricular assist device is then implanted depending on the level of support needed (LVAD, RVAD, BiVAD \pm oxygenator, total artificial heart). Where possible, the patient is then re-evaluated for a redoorthotopic heart transplantation.

\section{Levosimendan}

Levosimendan is a calcium sensitising agent and inodilator which increases cardiac contractility. Its primary mode of action is by increasing the sensitivity of troponin-C to calcium during systole thereby increasing cardiac performance without increasing myocardial oxygen consumption. It also reduces peripheral vascular resistances by opening of adenosine triphosphate-dependent $\mathrm{K}+$ channels [197]. It was initially used for treatment of cardiogenic shock post-acute myocardial infarction [197]. However, SURVIVE, a multicentre RCT evaluating levosimendan vs dobutamine in acute decompensated heart failure, revealed no differences in survival outcomes between the two groups [198].There was an initial reduction in plasma B-type natriuretic peptide level in patients in the levosimendan group compared with patients in the dobutamine group. Florian Weis and colleagues report a case series of 12 patients with PGD who received $0.1 \mu \mathrm{g} / \mathrm{kg} / \mathrm{min}$ levosimendan for PGD with a centre-specific definition of LVEF $<30 \%$ on transesophageal echocardiogram with a combination of adrenaline $>0.1 \mu \mathrm{g} / \mathrm{kg} / \mathrm{min}$ and the milrinone $>$ $0.3 \mu \mathrm{g} / \mathrm{kg} / \mathrm{min}$ [199]. Eleven of the 12 patients survived beyond 30 days, with significant reductions in inotropic support without requiring mechanical circulatory support. However, follow-up studies by the same group showed significantly lower 1-year and 3-year survival rates [200].

The inotropic effects of levosimendan may often take hours to develop, which may be offset by its potent vasodilation capacity [201]. It may however also play a role in protecting cardiomyocytes against ischaemic/reperfusion injury by 
activating adenosine triphosphate-sensitive potassium channels in mitochondria as shown by numerous studies although to date, no studies have been done on pre-or post-conditioning in a heart transplant setting [202-206].

\section{Plasmapheresis}

Plasmapheresis is a process by which whole blood is passed through a filter to separate the plasma components from the larger cellular components of red blood cells, white blood cells and platelets [207]. Its use in transplantation was primarily for hyperacute or acute humoral rejection, whereby adjunctive therapeutic plasma exchange has been used alongside immunosuppression and intravenous immunoglobulins to improve survival of incompatible organs compared to compatible organs [208]. Plasmapheresis rapidly reduces the circulating antibodies and thereby improves cardiac function [209]. Plasmapheresis has been used for primary allograft dysfunction after liver transplantation with encouraging results [210, 211]. A study by a group in Taiwan revealed treatment with pulsed steroid and plasmapheresis improved the ejection fraction and NYHA status of $>70 \%$ of the patients treated [212]. However, the definitions of PGD in this cohort were not discernible from acute rejection due to the study methodology and lack of biopsy-proven rejection at the time of treatment as treatment was started empirically in all 35 patients who were in NYHA functional class III or IV requiring pharmacological or mechanical circulatory support. The Cedars-Sinai Heart Institute group performed a similar study in patients with severe PGD. In their cohort of 15 patients, $66 \%$ of whom underwent plasmapheresis post-transplantation had significantly improved outcomes compared to the $33 \%$ of severe PGD patients who did not. They concluded that the potential role of inflammatory molecule depletion in these patients may play a role in the pathophysiology of PGD [213]. The exact role of plasmapheresis in PGD is still speculative and may potentially be clearer with ongoing research.

\section{Conclusion}

PGD is the leading cause of early morbidity and mortality following heart transplantation. It is thought to be multifactorial in origin and several risk factors implicated. The search for an accurate biomarker however remains elusive. Treatment options to date remain supportive with no definitive pharmacological agents identified as of yet. Plasmapheresis may have a role in depletion of inflammatory chemokines and cytokines for treatment of PGD.

Open Access This article is distributed under the terms of the Creative Commons Attribution 4.0 International License (http:// creativecommons.org/licenses/by/4.0/), which permits unrestricted use, distribution, and reproduction in any medium, provided you give appropriate credit to the original author(s) and the source, provide a link to the Creative Commons license, and indicate if changes were made.

\section{References}

1. Lund LH, Khush KK, Cherikh WS, Goldfarb S, Kucheryavaya AY, Levvey BJ et al (2017) The Registry of the International Society for Heart and Lung Transplantation: thirty-fourth adult heart transplantation report; focus theme: allograft ischemic time. J Heart Lung Transplant 36(10):1037-1046

2. Lund LH, Edwards LB, Kucheryavaya AY, Dipchand AI, Benden C, Christie JD et al (2013) The Registry of the International Society for Heart and Lung Transplantation: thirtieth official adult heart transplant report-2013; focus theme: age. J Heart Lung Transplant 32(10):951-964

3. Segovia J, Pulpón LA, Sanmartín M, Tejero C, Serrano S, Burgos $R$ et al (1998) Primary graft failure in heart transplantation: a multivariate analysis. Transplant Proc 30(5):1932

4. Russo MJ, Iribarne A, Hong KN, Ramlawi B, Chen JM, Takayama $\mathrm{H}$ et al (2010) Factors associated with primary graft failure after heart transplantation. Transplantation. 90(4):444-450

5. Iyer A, Kumarasinghe G, Hicks M, Watson A, Gao L, Doyle A et al (2011) Primary graft failure after heart transplantation. J Transplant 2011:175768

6. Kobashigawa J, Zuckermann A, Macdonald P, Leprince P, Esmailian F, Luu M et al (2014) Report from a consensus conference on primary graft dysfunction after cardiac transplantation. $\mathrm{J}$ Heart Lung Transplant 33(4):327-340

7. Wernovsky G, Wypij D, Jonas RA, Mayer JE Jr, Hanley FL, Hickey PR et al (1995) Postoperative course and hemodynamic profile after the arterial switch operation in neonates and infants. A comparison of low-flow cardiopulmonary bypass and circulatory arrest. Circulation. 92(8):2226-2235

8. Dronavalli VB, Rogers CA, Banner NR (2015) Primary cardiac allograft dysfunction-validation of a clinical definition. Transplantation. 99(9):1919-1925

9. D'Alessandro C, Aubert S, Golmard JL, Praschker BL, Luyt CE, Pavie A et al (2010) Extra-corporeal membrane oxygenation temporary support for early graft failure after cardiac transplantation. Eur J Cardiothorac Surg 37(2):343-349

10. Oto T, Excell L, Griffiths AP, Levvey BJ, Bailey M, Marasco S et al (2008) Association between primary graft dysfunction among lung, kidney and heart recipients from the same multiorgan donor. Am J Transplant 8(10):2132-2139

11. Ibrahim M, Hendry P, Masters R, Rubens F, Lam BK, Ruel M et al (2007) Management of acute severe perioperative failure of cardiac allografts: a single-centre experience with a review of the literature. Can J Cardiol 23(5):363-367

12. Chew HC, Kumarasinghe G, Iyer A, Hicks M, Gao L, Doyle A et al (2014) Primary graft dysfunction after heart transplantation. Curr Transplant Rep 1(4):257-265

13. Gordon JK, McKinlay J (2012) Physiological changes after brain stem death and management of the heart-beating donor. Contin Educ Anaesth Crit Care Pain 12(5):225-229

14. Dictus C, Vienenkoetter B, Esmaeilzadeh M, Unterberg A, Ahmadi R (2009) Critical care management of potential organ donors: our current standard. Clin Transpl 23(Suppl 21):2-9

15. Shivalkar B, Van Loon J, Wieland W, Tjandra-Maga TB, Borgers M, Plets C et al (1993) Variable effects of explosive or gradual increase of intracranial pressure on myocardial structure and function. Circulation. 87(1):230-239

16. Souter MJ, Eidbo E, Findlay JY, Lebovitz DJ, Moguilevitch M, Neidlinger NA et al (2017) Organ donor management: part 1. 
Toward a consensus to guide anesthesia services during donation after brain death. Semin Cardiothorac Vasc Anesth 22(2):211-222

17. Rosendale JD, Kauffman HM, McBride MA, Chabalewski FL, Zaroff JG, Garrity ER et al (2003) Hormonal resuscitation yields more transplanted hearts, with improved early function. Transplantation. 75(8):1336-1341

18. Meers CM, Wauters S, Verbeken E, Scheers H, Vanaudenaerde B, Verleden GM et al (2011) Preemptive therapy with steroids but not macrolides improves gas exchange in caustic-injured donor lungs. J Surg Res 170(1):e141-e1e8

19. Venkateswaran RV, Patchell VB, Wilson IC, Mascaro JG, Thompson RD, Quinn DW et al (2008) Early donor management increases the retrieval rate of lungs for transplantation. Ann Thorac Surg 85(1):278-286

20. Wood KE, Becker BN, McCartney JG, D'Alessandro AM, Coursin DB (2004) Care of the potential organ donor. N Engl J Med 351(26):2730-2739

21. Kumar TKS, Mathis C, Sathanandam S, Zurakowski D, Subramanian S, Allen J et al (2017) Effect of thyroid hormone on cardiac function following orthotopic heart transplantation in piglets. Pediatr Transplant 21(6)

22. Novitzky D, Mi Z, Collins JF, Cooper DK (2015) Increased procurement of thoracic donor organs after thyroid hormone therapy. Semin Thorac Cardiovasc Surg 27(2):123-132

23. Schipper DA, Marsh KM, Ferng AS, Duncker DJ, Laman JD, Khalpey Z (2016) The critical role of bioenergetics in donor cardiac allograft preservation. J Cardiovasc Transl Res 9(3):176-183

24. Belzer FO, Southard JH (1988) Principles of solid-organ preservation by cold storage. Transplantation. 45(4):673-676

25. Marelli D, Laks H, Fazio D, Moore S, Moriguchi J, Kobashigawa J (2000) The use of donor hearts with left ventricular hypertrophy. J Heart Lung Transplant 19(5):496-503

26. Anaya-Prado R, Delgado-Vazquez JA (2008) Scientific basis of organ preservation. Curr Opin Organ Transplant 13(2):129-134

27. Vigne $\mathrm{P}$, Frelin C, Lazdunski M (1985) The $\mathrm{Na}+\mathrm{H}+$ exchanger in eukaryotic cells: biochemical and pharmacological properties and physiological role. Biochimie. 67(1):129-135

28. Karmazyn M, Gan XT, Humphreys RA, Yoshida H, Kusumoto K (1999) The myocardial $\mathrm{Na}(+)-\mathrm{H}(+)$ exchange: structure, regulation, and its role in heart disease. Circ Res 85(9):777-786

29. Marasco SF, Kras A, Schulberg E, Vale M, Lee GA (2012) Impact of warm ischemia time on survival after heart transplantation. Transplant Proc 44(5):1385-1389

30. Braunwald E, Kloner RA (1985) Myocardial reperfusion: a double-edged sword? J Clin Invest 76(5):1713-1719

31. Morciano G, Bonora M, Campo G, Aquila G, Rizzo P, Giorgi C et al (2017) Mechanistic role of mPTP in ischemia-reperfusion injury. In: Santulli G (ed) Mitochondrial dynamics in cardiovascular medicine. Springer International Publishing, Cham, pp 169-189

32. Penna C, Perrelli MG, Pagliaro P (2013) Mitochondrial pathways, permeability transition pore, and redox signaling in cardioprotection: therapeutic implications. Antioxid Redox Signal 18(5):556-599

33. Argaud L, Gateau-Roesch O, Raisky O, Loufouat J, Robert D, Ovize M (2005) Postconditioning inhibits mitochondrial permeability transition. Circulation. 111(2):194-197

34. Upadhaya S, Madala S, Baniya R, Subedi SK, Saginala K, Bachuwa $G$ (2017) Impact of cyclosporine A use in the prevention of reperfusion injury in acute myocardial infarction: a meta-analysis. Cardiol J 24(1):43-50

35. Hausenloy D, Wynne A, Duchen M, Yellon D (2004) Transient mitochondrial permeability transition pore opening mediates preconditioning-induced protection. Circulation. 109(14):1714-1717

36. Birnbaum Y, Hale SL, Kloner RA (1997) Ischemic preconditioning at a distance: reduction of myocardial infarct size by partial reduction of blood supply combined with rapid stimulation of the gastrocnemius muscle in the rabbit. Circulation 96(5):1641-1646

37. Liu GS, Thornton J, Van Winkle DM, Stanley AW, Olsson RA, Downey JM (1991) Protection against infarction afforded by preconditioning is mediated by A1 adenosine receptors in rabbit heart. Circulation. 84(1):350-356

38. Thielmann M, Kottenberg E, Kleinbongard P, Wendt D, Gedik N, Pasa $S$ et al (2013) Cardioprotective and prognostic effects of remote ischaemic preconditioning in patients undergoing coronary artery bypass surgery: a single-centre randomised, double-blind, controlled trial. Lancet (London, England) 382(9892):597-604

39. Benstoem C, Stoppe C, Liakopoulos OJ, Ney J, Hasenclever D, Meybohm P et al (2017) Remote ischaemic preconditioning for coronary artery bypass grafting (with or without valve surgery). Cochrane Database Syst Rev 5:Cd011719

40. D'Ascenzo F, Cavallero E, Moretti C, Omede P, Sciuto F, Rahman IA et al (2012) Remote ischaemic preconditioning in coronary artery bypass surgery: a meta-analysis. Heart. 98(17):1267-1271

41. Hausenloy DJ, Candilio L, Evans R, Ariti C, Jenkins DP, Kolvekar $\mathrm{S}$ et al (2015) Remote ischemic preconditioning and outcomes of cardiac surgery. N Engl J Med 373(15):1408-1417

42. Pierce B, Bole I, Patel V, Brown DL. Clinical outcomes of remote ischemic preconditioning prior to cardiac surgery: a meta-analysis of randomized controlled trials. J Am Heart Assoc. 2017;6(2)

43. Meybohm P, Kohlhaas M, Stoppe C, Gruenewald M, Renner J, Bein B, et al. RIPHeart (Remote Ischemic Preconditioning for Heart Surgery) study: myocardial dysfunction, postoperative neurocognitive dysfunction, and 1 year follow-up. J Am Heart Assoc. 2018;7(7)

44. Kleinbongard P, Neuhauser M, Thielmann M, Kottenberg E, Peters J, Jakob H et al (2016) Confounders of cardioprotection by remote ischemic preconditioning in patients undergoing coronary artery bypass grafting. Cardiology. 133(2):128-133

45. Konstantinov IE, Li J, Cheung MM, Shimizu M, Stokoe J, Kharbanda RK et al (2005) Remote ischemic preconditioning of the recipient reduces myocardial ischemia-reperfusion injury of the denervated donor heart via a Katp channel-dependent mechanism. Transplantation. 79(12):1691-1695

46. Nieszner E, Posa I, Kocsis E, Pogatsa G, Preda I, Koltai MZ (2002) Influence of diabetic state and that of different sulfonylureas on the size of myocardial infarction with and without ischemic preconditioning in rabbits. Exp Clin Endocrinol Diabetes 110(5):212-218

47. Ishihara M, Inoue I, Kawagoe T, Shimatani Y, Kurisu S, Nishioka $\mathrm{K}$ et al (2001) Diabetes mellitus prevents ischemic preconditioning in patients with a first acute anterior wall myocardial infarction. J Am Coll Cardiol 38(4):1007-1011

48. Kristiansen SB, Lofgren B, Stottrup NB, Khatir D, Nielsen-Kudsk JE, Nielsen TT et al (2004) Ischaemic preconditioning does not protect the heart in obese and lean animal models of type 2 diabetes. Diabetologia. 47(10):1716-1721

49. Crisostomo PR, Wang M, Wairiuko GM, Terrell AM, Meldrum DR (2006) Postconditioning in females depends on injury severity. J Surg Res 134(2):342-347

50. Heinen A, Behmenburg F, Aytulun A, Dierkes M, Zerbin L, Kaisers W et al (2018) The release of cardioprotective humoral factors after remote ischemic preconditioning in humans is ageand sex-dependent. J Transl Med 16(1):112

51. Moolman JA, Genade S, Tromp E, Opie LH, Lochner A (1997) Ischaemic preconditioning does not protect hypertrophied myocardium against ischaemia. S Afr Med J = Suid-Afrikaanse tydskrif vir geneeskunde 87(Suppl 3):C151-C156

52. Ebrahim Z, Yellon DM, Baxter GF (2007) Ischemic preconditioning is lost in aging hypertensive rat heart: independent effects of aging and longstanding hypertension. Exp Gerontol 42(8):807-814 
53. Bartling B, Friedrich I, Silber RE, Simm A (2003) Ischemic preconditioning is not cardioprotective in senescent human myocardium. Ann Thorac Surg 76(1):105-111

54. Nichols CG, Lederer WJ (1990) The role of ATP in energydeprivation contractures in unloaded rat ventricular myocytes. Can J Physiol Pharmacol 68(2):183-194

55. Schluter KD, Jakob G, Ruiz-Meana M, Garcia-Dorado D, Piper HM (1996) Protection of reoxygenated cardiomyocytes against osmotic fragility by nitric oxide donors. Am J Phys 271(2 Pt 2): H428-H434

56. Piper HM, Abdallah Y, Schäfer C (2004) The first minutes of reperfusion: a window of opportunity for cardioprotection. Cardiovasc Res 61(3):365-371

57. Inserte J, Garcia-Dorado D, Hernando V, Soler-Soler J (2005) Calpain-mediated impairment of $\mathrm{Na}+\mathrm{K}+$-ATPase activity during early reperfusion contributes to cell death after myocardial ischemia. Circ Res 97(5):465-473

58. Garcia-Dorado D, Rodriguez-Sinovas A, Ruiz-Meana M, Inserte J, Agulló L, Cabestrero A (2006) The end-effectors of preconditioning protection against myocardial cell death secondary to ischemia-reperfusion. Cardiovasc Res 70(2):274-285

59. Garcia-Dorado D, Rodriguez-Sinovas A, Ruiz-Meana M (2004) Gap junction-mediated spread of cell injury and death during myocardial ischemia-reperfusion. Cardiovasc Res 61(3):386-401

60. White CW, Messer SJ, Large SR, Conway J, Kim DH, Kutsogiannis DJ et al (2018) Transplantation of hearts donated after circulatory death. Front Cardiovasc Med 5:8

61. White CW, Lillico R, Sandha J, Hasanally D, Wang F, Ambrose E et al (2016) Physiologic changes in the heart following cessation of mechanical ventilation in a porcine model of donation after circulatory death: implications for cardiac transplantation. Am J Transplant Off J Am Soc Transplant Am Soc Transplant Surg 16(3):783-793

62. Manara AR, Murphy PG, O'Callaghan G (2012) Donation after circulatory death. Br J Anaesth 108(suppl_1):i108-ii21

63. Page A, Messer S, Large SR (2018) Heart transplantation from donation after circulatory determined death. Ann Cardiothorac Surg 7(1):75-81

64. Chan JL, Kobashigawa JA, Aintablian TL, Li Y, Perry PA, Patel JK et al (2017) Vasoplegia after heart transplantation: outcomes at 1 yeart. Interact Cardiovasc Thorac Surg 25(2):212-217

65. Omar S, Zedan A, Nugent K (2015) Cardiac vasoplegia syndrome: pathophysiology, risk factors and treatment. Am J Med Sci 349(1):80-88

66. Rylski B, Berchtold-Herz M, Olschewski M, Zeh W, Schlensak C, Siepe M et al (2010) Reducing the ischemic time of donor hearts will decrease morbidity and costs of cardiac transplantationst 2 . Interact Cardiovasc Thorac Surg 10(6):945-947

67. Stobierska-Dzierzek B, Awad H, Michler RE (2001) The evolving management of acute right-sided heart failure in cardiac transplant recipients. J Am Coll Cardiol 38(4):923-931

68. Russo MJ, Chen JM, Sorabella RA, Martens TP, Garrido M, Davies RR et al (2007) The effect of ischemic time on survival after heart transplantation varies by donor age: an analysis of the United Network for Organ Sharing database. J Thorac Cardiovasc Surg 133(2):554-559

69. Loebe M, Potapov EV, Hummel M, Weng Y, Bocksch W, Hetzer $\mathrm{R}$ (2000) Medium-term results of heart transplantation using older donor organs. J Heart Lung Transplant 19(10):957-963

70. Lietz K, John R, Mancini DM, Edwards NM (2004) Outcomes in cardiac transplant recipients using allografts from older donors versus mortality on the transplant waiting list: implications for donor selection criteria. J Am Coll Cardiol 43(9):1553-1561

71. Blanche C, Kamlot A, Blanche DA, Kearney B, Magliato KE, Czer LSC et al (2002) Heart transplantation with donors fifty years of age and older. J Thorac Cardiovasc Surg 123(4):810-815
72. Potapov EV, Loebe M, Hubler M, Musci M, Hummel M, Weng Y et al (1999) Medium-term results of heart transplantation using donors over 63 years of age. Transplantation. 68(12):1834-1838

73. Croome KP, Dan S, Roberto HA, Adams PC, Alan T, Natasha C (2014) Female donor to male recipient gender discordance results in inferior graft survival: a prospective study of 1,042 liver transplants. J Hepatobiliary Pancreat Sci 21(4):269-274

74. Gratwohl A, Hermans J, Niederwieser D, van Biezen A, van Houwelingen HC, Apperley J et al (2001) Female donors influence transplant-related mortality and relapse incidence in male recipients of sibling blood and marrow transplants. Hematol J 2(6):363-370

75. Kongtim P, Di Stasi A, Rondon G, Chen J, Adekola K, Popat U et al (2015) Can a female donor for a male recipient decrease the relapse rate for patients with acute myeloid leukemia treated with allogeneic hematopoietic stem cell transplantation? Biol Blood Marrow Transplant 21(4):713-719

76. Yamani MH, Lauer MS, Starling RC, Pothier CE, Tuzcu EM, Ratliff NB et al (2004) Impact of donor spontaneous intracranial hemorrhage on outcome after heart transplantation. Am J Transplant 4(2):257-261

77. Shanlin RJ, Sole MJ, Rahimifar M, Tator CH, Factor SM (1988) Increased intracranial pressure elicits hypertension, increased sympathetic activity, electrocardiographic abnormalities and myocardial damage in rats. J Am Coll Cardiol 12(3):727-736

78. Tsai FC, Marelli D, Bresson J, Gjertson D, Kermani R, Patel J et al (2002) Use of hearts transplanted from donors with atraumatic intracranial bleeds. J Heart Lung Transplant 21(6):623-628

79. Lima B, Rajagopal K, Petersen RP, Shah AS, Soule B, Felker GM et al (2006) Marginal cardiac allografts do not have increased primary graft dysfunction in alternate list transplantation. Circulation. 114(1 Suppl):I27-I32

80. Goland S, Czer LS, Kass RM, Siegel RJ, Mirocha J, De Robertis MA et al (2008) Use of cardiac allografts with mild and moderate left ventricular hypertrophy can be safely used in heart transplantation to expand the donor pool. J Am Coll Cardiol 51(12):1214-1220

81. Felker GM, Milano CA, Yager JE, Hernandez AF, Blue L, Higginbotham MB et al (2005) Outcomes with an alternate list strategy for heart transplantation. J Heart Lung Transplant 24(11): 1781-1786

82. Pinzon OW, Stoddard G, Drakos SG, Gilbert EM, Nativi JN, Budge D et al (2011) Impact of donor left ventricular hypertrophy on survival after heart transplant. Am J Transplant Off J Am Soc Transplant Am Soc Transplant Surg 11(12):2755-2761

83. Aziz S, Soine LA, Lewis SL, Kruse AP, Levy WC et al (1997) Donor left ventricular hypertrophy increases risk for early graft failure. Transpl Int 10(6):446-450

84. Kuppahally SS, Valantine HA, Weisshaar D, Parekh H, Hung YY, Haddad F et al (2007) Outcome in cardiac recipients of donor hearts with increased left ventricular wall thickness. Am J Transplant Off J Am Soc Transplant Am Soc Transplant Surg 7(10):2388-2395

85. Stehlik J, Edwards LB, Kucheryavaya AY, Aurora P, Christie JD, Kirk R et al (2010) The Registry of the International Society for Heart and Lung Transplantation: twenty-seventh official adult heart transplant report-2010. J Heart Lung Transplant 29(10): 1089-1103

86. Dunn FG, Pringle SD (1987) Left ventricular hypertrophy and myocardial ischemia in systemic hypertension. Am J Cardiol 60(17):19-22

87. García Sáez D, Zych B, Sabashnikov A, Bowles CT, De Robertis F, Mohite PN et al (2014) Evaluation of the organ care system in heart transplantation with an adverse donor/recipient profile. Ann Thorac Surg 98(6):2099-2106

88. Costanzo MR, Dipchand A, Starling R, Anderson A, Chan M, Desai $S$ et al (2010) The International Society of Heart and Lung 
Transplantation Guidelines for the care of heart transplant recipients. J Heart Lung Transplant 29(8):914-956

89. Movahed A, Reeves WC, Mehta PM, Gilliland MG, Mozingo SL, Jolly SR (1994) Norepinephrine-induced left ventricular dysfunction in anesthetized and conscious, sedated dogs. Int J Cardiol 45(1):23-33

90. D'Alessandro C, Golmard JL, Barreda E, Laali M, Makris R, Luyt $\mathrm{CE}$ et al (2011) Predictive risk factors for primary graft failure requiring temporary extra-corporeal membrane oxygenation support after cardiac transplantation in adults. Eur J Cardiothorac Surg 40(4):962-969

91. Santise G, D'Ancona G, Falletta C, Pirone F, Sciacca S, Turrisi M et al (2009) Donor pharmacological hemodynamic support is associated with primary graft failure in human heart transplantation. Interact Cardiovasc Thorac Surg 9(3):476-479

92. Segovia J, Cosio MD, Barcelo JM, Bueno MG, Pavia PG, Burgos $\mathrm{R}$ et al (2011) RADIAL: a novel primary graft failure risk score in heart transplantation. J Heart Lung Transplant 30(6):644-651

93. McKeown DW, Bonser RS, Kellum JA (2012) Management of the heartbeating brain-dead organ donor. Br J Anaesth 108(suppl_1):i96-i107

94. Yoshioka T, Sugimoto H, Uenishi M, Sakamoto T, Sadamitsu D, Sakano T et al (1986) Prolonged hemodynamic maintenance by the combined administration of vasopressin and epinephrine in brain death: a clinical study. Neurosurgery. 18(5):565-567

95. Venkateswaran RV, Steeds RP, Quinn DW, Nightingale P, Wilson IC, Mascaro JG et al (2009) The haemodynamic effects of adjunctive hormone therapy in potential heart donors: a prospective randomized double-blind factorially designed controlled trial. Eur Heart J 30(14):1771-1780

96. Hong KN, Iribarne A, Worku B, Takayama H, Gelijns AC, Naka Y et al (2011) Who is the high-risk recipient? Predicting mortality after heart transplant using pretransplant donor and recipient risk factors. Ann Thorac Surg 92(2):520-527

97. Young JB, Hauptman PJ, Naftel DC, Ewald G, Aaronson K, Dec GW et al (2001) Determinants of early graft failure following cardiac transplantation, a 10-year, multi-institutional, multivariable analysis. J Heart Lung Transplant 20(2):212

98. Truby LK, Takeda K, Topkara VK, Takayama H, Garan AR, Yuzefpolskaya $\mathrm{M}$ et al (2018) Risk of severe primary graft dysfunction in patients bridged to heart transplantation with continuous-flow left ventricular assist devices. J Heart Lung Transplant 37(12):1433-1442

99. Kirklin JK, Pagani FD, Kormos RL, Stevenson LW, Blume ED, Myers SL et al (2017) Eighth annual INTERMACS report: special focus on framing the impact of adverse events. J Heart Lung Transplant 36(10):1080-1086

100. Foroutan F, Ross HJ (2019) Primary graft dysfunction: the devil is in the details. Transplantation. 103(2):229-230

101. Foroutan F, Alba AC, Guyatt G, Duero Posada J, Ng Fat Hing N, Arseneau E et al (2018) Predictors of 1-year mortality in heart transplant recipients: a systematic review and meta-analysis. Heart. 104(2):151-160

102. Taghavi S, Jayarajan SN, Wilson LM, Komaroff E, Testani JM, Mangi AA (2013) Cardiac transplantation can be safely performed using selected diabetic donors. J Thorac Cardiovasc Surg 146(2): 442-447

103. Singh TP, Almond CS, Semigran MJ, Piercey G, Gauvreau K (2012) Risk prediction for early in-hospital mortality following heart transplantation in the United States. Circ Heart Fail 5(2):259-266

104. Yeom SY, Hwang HY, Oh S-J, Cho H-J, Lee H-Y, Kim K-B (2013) Heart transplantation in the elderly patients: midterm results. Korean J Thorac Cardiovasc Surg 46(2):111-116

105. Bull DA, Karwande SV, Hawkins JA, Neumayer LA, Taylor DO, Jones KW et al (1996) Long-term results of cardiac transplantation in patients older than sixty years. UTAH Cardiac Transplant Program. J Thorac Cardiovasc Surg 111(2):423-427 discussion 7-8

106. Tjang YS, van der Heijden GJ, Tenderich G, Korfer R, Grobbee DE (2008) Impact of recipient's age on heart transplantation outcome. Ann Thorac Surg 85(6):2051-2055

107. Morales D, Williams E, John R (2010) Is resternotomy in cardiac surgery still a problem? 2 s. Interact Cardiovasc Thorac Surg 11(3): 277-286

108. Kuralay E, Bolcal C, Cingoz F, Gunay C, Yildirim V, Kilic S et al (2004) Cardiac reoperation by Carpentier bicaval femoral venous cannula: GATA experience. Ann Thorac Surg 77(3):977-981 discussion 82

109. Still S, Shaikh AF, Qin H, Felius J, Jamil AK, Saracino G et al (2018) Reoperative sternotomy is associated with primary graft dysfunction following heart transplantation. Interact Cardiovasc Thorac Surg

110. Awad M, Czer LS, Mirocha J, Ruzza A, Rafiei M, Reich H et al (2015) Prior sternotomy increases the mortality and morbidity of adult heart transplantation. Transplant Proc 47(2):485-497

111. Kansara P, Czer L, Awad M, Arabia F, Mirocha J, De Robertis M et al (2014) Heart transplantation with and without prior sternotomy: analysis of the United Network for Organ Sharing database. Transplant Proc 46(1):249-255

112. Santangeli P, Rame JE, Birati EY, Marchlinski FE (2017) Management of ventricular arrhythmias in patients with advanced heart failure. J Am Coll Cardiol 69(14):1842-1860

113. Macdonald P, Hackworthy R, Keogh A, Sivathasan C, Chang V, Spratt P (1991) The effect of chronic amiodarone therapy before transplantation on early cardiac allograft function. J Heart Lung Transplant 10(5 Pt 1):743-748 discussion 8-9

114. Chelimsky-Fallick C, Middlekauff HR, Stevenson WG, Kobashigawa J, Saxon LA, Moriguchi J et al (1992) Amiodarone therapy does not compromise subsequent heart transplantation. J Am Coll Cardiol 20(7):1556-1561

115. Rivinius R, Helmschrott M, Ruhparwar A, Schmack B, Erbel C, Gleissner CA et al (2016) Long-term use of amiodarone before heart transplantation significantly reduces early post-transplant atrial fibrillation and is not associated with increased mortality after heart transplantation. Drug Des Devel Ther 10:677-686

116. Wright M, Takeda K, Mauro C, Jennings D, Kurlansky P, Han J et al (2017) Dose-dependent association between amiodarone and severe primary graft dysfunction in orthotopic heart transplantation. J Heart Lung Transplant 36(11):1226-1233

117. Chin C, Feindel C, Cheng D (1999) Duration of preoperative amiodarone treatment may be associated with postoperative hospital mortality in patients undergoing heart transplantation. J Cardiothorac Vasc Anesth 13(5):562-566

118. Halazun KJ, Al-Mukhtar A, Aldouri A, Willis S, Ahmad N (2007) Warm ischemia in transplantation: search for a consensus definition. Transplant Proc 39(5):1329-1331

119. Squiers JJ, Saracino G, Chamogeorgakis T, MacHannaford JC, Rafael AE, Gonzalez-Stawinski GV et al (2017) Application of the International Society for Heart and Lung Transplantation (ISHLT) criteria for primary graft dysfunction after cardiac transplantation: outcomes from a high-volume centredagger. Eur J Cardiothorac Surg 51(2):263-270

120. Banner NR, Thomas HL, Curnow E, Hussey JC, Rogers CA, Bonser RS (2008) The importance of cold and warm cardiac ischemia for survival after heart transplantation. Transplantation. 86(4):542-547

121. Wong G, Teixeira-Pinto A, Chapman JR, Craig JC, Pleass H, McDonald $\mathrm{S}$ et al (2017) The impact of total ischemic time, donor age and the pathway of donor death on graft outcomes after deceased donor kidney transplantation. Transplantation. 101(6): $1152-1158$ 
122. Salis S, Mazzanti VV, Merli G, Salvi L, Tedesco CC, Veglia F et al (2008) Cardiopulmonary bypass duration is an independent predictor of morbidity and mortality after cardiac surgery. $\mathrm{J}$ Cardiothorac Vasc Anesth 22(6):814-822

123. Kirklin JW (1980) Open-heart surgery at the Mayo Clinic. The 25th anniversary. Mayo Clin Proc 55(5):339-341

124. Anselmi A, Abbate A, Girola F, Nasso G, Biondi-Zoccai GG, Possati G et al (2004) Myocardial ischemia, stunning, inflammation, and apoptosis during cardiac surgery: a review of evidence. Eur J Cardiothorac Surg 25(3):304-311

125. Murphy GJ, Reeves BC, Rogers CA, Rizvi SI, Culliford L, Angelini GD (2007) Increased mortality, postoperative morbidity, and cost after red blood cell transfusion in patients having cardiac surgery. Circulation. 116(22):2544-2552

126. Koch CG, Li L, Duncan AI, Mihaljevic T, Cosgrove DM, Loop FD et al (2006) Morbidity and mortality risk associated with red blood cell and blood-component transfusion in isolated coronary artery bypass grafting. Crit Care Med 34(6):1608-1616

127. Kuduvalli M, Oo AY, Newall N, Grayson AD, Jackson M, Desmond MJ et al (2005) Effect of peri-operative red blood cell transfusion on 30-day and 1-year mortality following coronary artery bypass surgery. Eur J Cardiothorac Surg 27(4):592-598

128. Reed RM, Netzer G, Hunsicker L, Mitchell BD, Rajagopal K, Scharf S et al (2014) Cardiac size and sex-matching in heart transplantation: size matters in matters of sex and the heart. JACC Heart Fail 2(1):73-83

129. Smits JM, Vanhaecke J, Haverich A, de Vries E, Smith M, Rutgrink E et al (2003) Three-year survival rates for all consecutive heart-only and lung-only transplants performed in Eurotransplant, 1997-1999. Clin Transpl:89-100

130. Patel ND, Weiss ES, Nwakanma LU, Russell SD, Baumgartner WA, Shah AS et al (2008) Impact of donor-to-recipient weight ratio on survival after heart transplantation: analysis of the United Network for Organ Sharing Database. Circulation. 118(14 Suppl):S83-S88

131. Weiss ES, Allen JG, Patel ND, Russell SD, Baumgartner WA, Shah AS et al (2009) The impact of donor-recipient sex matching on survival after orthotopic heart transplantation: analysis of 18 000 transplants in the modern era. Circ Heart Fail 2(5):401-408

132. Stehlik J, Feldman DS, Brown RN, VanBakel AB, Russel SD, Ewald GA et al (2010) Interactions among donor characteristics influence post-transplant survival: a multi-institutional analysis. J Heart Lung Transplant 29(3):291-298

133. Jayarajan SN, Taghavi S, Komaroff E, Mangi AA (2013) Impact of low donor to recipient weight ratios on cardiac transplantation. J Thorac Cardiovasc Surg 146(6):1538-1543

134. Murphy K, Kransdorf EP, Wilansky S, Pajaro OE, Steidley DE (2016) Impact of size mismatch on heart transplant outcomes. J Heart Lung Transplant 35(4):S214-S2S5

135. Kertesz NJ, Gajarski RJ, Towbin JA, Geva T (1995) Effect of donor-recipient size mismatch on left ventricular remodeling after pediatric orthotopic heart transplantation. Am J Cardiol 76(16): $1167-1172$

136. Locksley RM, Killeen N, Lenardo MJ (2001) The TNF and TNF receptor superfamilies: integrating mammalian biology. Cell. 104(4):487-501

137. Cui X, Chang L, Li Y, Lv Q, Wang F, Lin Y et al (2018) Trivalent soluble TNF receptor, a potent TNF-alpha antagonist for the treatment collagen-induced arthritis. Sci Rep 8(1):7327

138. Mukhopadhyay S, Hoidal JR, Mukherjee TK (2006) Role of TNF $\alpha$ in pulmonary pathophysiology. Respir Res 7(1):125

139. Sack MN (2002) Tumor necrosis factor- $\alpha$ in cardiovascular biology and the potential role for anti-tumor necrosis factor- $\alpha$ therapy in heart disease. Pharmacol Ther 94(1):123-135
140. Levine B, Kalman J, Mayer L, Fillit HM, Packer M (1990) Elevated circulating levels of tumor necrosis factor in severe chronic heart failure. N Engl J Med 323(4):236-241

141. Birks EJ, Burton PB, Owen V, Mullen AJ, Hunt D, Banner NR et al (2000) Elevated tumor necrosis factor-alpha and interleukin-6 in myocardium and serum of malfunctioning donor hearts. Circulation 102(19 Suppl 3):Iii352-Iii358

142. Tatham KC, O'Dea KP, Romano R, Donaldson HE, Wakabayashi $\mathrm{K}$, Patel BV et al (2018) Intravascular donor monocytes play a central role in lung transplant ischaemia-reperfusion injury. Thorax. 73(4):350-360

143. Schnickel GT, Ross DJ, Beygui R, Shefizadeh A, Laks H, Saggar $\mathrm{R}$ et al (2006) Modified reperfusion in clinical lung transplantation: the results of 100 consecutive cases. J Thorac Cardiovasc Surg 131(1):218-223

144. Venkateswaran RV, Dronavalli V, Lambert PA, Steeds RP, Wilson IC, Thompson RD et al (2009) The proinflammatory environment in potential heart and lung donors: prevalence and impact of donor management and hormonal therapy. Transplantation. 88(4):582-588

145. Braulio R, Sanches MD, Teixeira Junior AL, Costa PHN, Moreira MCV, Rocha MA et al (2016) Associated clinical and laboratory markers of donor on allograft function after heart transplant. Braz J Cardiovasc Surg 31(2):89-97

146. Tanaka T, Narazaki M, Kishimoto T (2014) IL-6 in inflammation, immunity, and disease. Cold Spring Harb Perspect Biol 6(10): a016295

147. Fontes JA, Rose NR, Čiháková D (2015) The varying faces of IL-6: from cardiac protection to cardiac failure. Cytokine. 74(1):62-68

148. Plenz G, Eschert H, Erren M, Wichter T, Böhm M, Flesch M et al (2002) The interleukin-6/interleukin-6-receptorsystem is activated in donor hearts. J Am Coll Cardiol 39(9):1508-1512

149. Moreno I, Vicente R, Ramos F, Vicente JL, Barbera M (2007) Determination of interleukin-6 in lung transplantation: association with primary graft dysfunction. Transplant Proc 39(7):2425-2426

150. Kukielka GL, Smith CW, Manning AM, Youker KA, Michael LH, Entman ML (1995) Induction of interleukin-6 synthesis in the myocardium. Potential role in postreperfusion inflammatory injury. Circulation. 92(7):1866-1875

151. Gwechenberger M, Mendoza LH, Youker KA, Frangogiannis NG, Smith CW, Michael LH et al (1999) Cardiac myocytes produce interleukin-6 in culture and in viable border zone of reperfused infarctions. Circulation. 99(4):546-551

152. Jin M, Khan AI (2010) Procalcitonin: uses in the clinical laboratory for the diagnosis of sepsis. Lab Med 41(3):173-177

153. Sandkovsky U, Kalil AC, Florescu DF (2015) The use and value of procalcitonin in solid organ transplantation. Clin Transpl 29(8): 689-696

154. Yu XY, Wang Y, Zhong H, Dou QL, Song YL, Wen H (2014) Diagnostic value of serum procalcitonin in solid organ transplant recipients: a systematic review and meta-analysis. Transplant Proc 46(1):26-32

155. Madershahian N, Wittwer T, Strauch J, Wippermann J, Rahmanian P, Franke UF et al (2008) Kinetic of procalcitonin in the early postoperative course following heart transplantation. $\mathrm{J}$ Card Surg 23(5):468-473

156. Wagner FD, Jonitz B, Potapov EV, Qedra N, Wegscheider K, Abraham K et al (2001) Procalcitonin, a donor-specific predictor of early graft failure-related mortality after heart transplantation. Circulation. 104(12 Suppl 1):I192-I196

157. van Ree RM, de Vries AP, Oterdoom LH, Seelen MA, Gansevoort RT, Schouten JP et al (2009) Plasma procalcitonin is an independent predictor of graft failure late after renal transplantation. Transplantation. 88(2):279-287

158. Eyraud D, Ben Ayed S, Tanguy ML, Vezinet C, Siksik JM, Bernard M et al (2008) Procalcitonin in liver transplantation: are 
high levels due to donors or recipients? Crit Care (London, England) 12(4):R85

159. Sammons C, Doligalski CT (2014) Utility of procalcitonin as a biomarker for rejection and differentiation of infectious complications in lung transplant recipients. Ann Pharmacother 48(1):116122

160. Bhat T, Teli S, Rijal J, Bhat H, Raza M, Khoueiry G et al (2013) Neutrophil to lymphocyte ratio and cardiovascular diseases: a review. Expert Rev Cardiovasc Ther 11(1):55-59

161. Ucar FM, Acar B, Gul M, Ozeke O, Aydogdu S (2016) The association between platelet/lymphocyte ratio and coronary artery disease severity in asymptomatic low ejection fraction patients. Korean Circ J 46(6):821-826

162. Huang WM, Cheng HM, Huang CJ, Guo CY, Lu DY, Lee CW et al (2017) Hemographic indices are associated with mortality in acute heart failure. Sci Rep 7(1):17828

163. Yost G, Ibrahim K, Tatooles A, Bhat G (2017) Longitudinal neutrophil to lymphocyte ratio assessment after left ventricular assist device implantation. J Heart Lung Transplant 36(4):S349

164. Seropian IM, Romeo FJ, Pizarro R, Vulcano NO, Posatini RA, Marenchino RG et al (2018) Neutrophil-to-lymphocyte ratio and platelet-to-lymphocyte ratio as predictors of survival after heart transplantation. ESC Heart Fail 5(1):149-156

165. Hogendorf P, Suska A, Skulimowski A, Rut J, Grochowska M, Wencel A et al (2018) Neutrophil-lymphocyte ratio and creatinine reduction ratio predict good early graft function among adult cadaveric donor renal transplant recipients. Single institution series. Polski przeglad chirurgiczny 90(2):28-33

166. Yost G, Bhat G, Pappas P, Tatooles A (2018) The neutrophil to lymphocyte ratio in patients supported with extracorporeal membrane oxygenation. Perfusion. 267659118772455

167. Sharma S, Jackson PG, Makan J (2004) Cardiac troponins. J Clin Pathol 57(10):1025-1026

168. Dronavalli VB, Banner NR, Bonser RS (2010) Assessment of the potential heart donor: a role for biomarkers? J Am Coll Cardiol 56(5):352-361

169. Riou B, Dreux S, Roche S, Arthaud M, Goarin JP, Léger P et al (1995) Circulating cardiac troponin $\mathrm{T}$ in potential heart transplant donors. Circulation. 92(3):409-414

170. Potapov EV, Wagner FD, Loebe M, Ivanitskaia EA, Müller C, Sodian R et al (2003) Elevated donor cardiac troponin T and procalcitonin indicate two independent mechanisms of early graft failure after heart transplantation. Int J Cardiol 92(2):163-167

171. Vijay P, Scavo VA, Morelock RJ, Sharp TG, Brown JW (1998) Donor cardiac troponin T: a marker to predict heart transplant rejection. Ann Thorac Surg 66(6):1934-1939

172. Potapov EV, Ivanitskaia EA, Loebe M, Mückel M, Müller C, Sodian R et al (2001) Value of cardiac troponin I and T for selection of heart donors and as predictors of early graft failure. Transplantation. 71(10): 1394-1400

173. Deibert E, Aiyagari V, Diringer MN (2000) Reversible left ventricular dysfunction associated with raised troponin I after subarachnoid haemorrhage does not preclude successful heart transplantation. Heart. 84(2):205-207

174. Deibert E, Barzilai B, Braverman AC, Edwards DF, Aiyagari V, Dacey R et al (2003) Clinical significance of elevated troponin I levels in patients with nontraumatic subarachnoid hemorrhage. J Neurosurg 98(4):741-746

175. Boccheciampe N, Audibert G, Rangeard O, Charpentier C, Perrier JF, Lalot JM et al (2009) Serum troponin Ic values in organ donors are related to donor myocardial dysfunction but not to graft dysfunction or rejection in the recipients. Int J Cardiol 133(1):80-86

176. Khush KK, Menza RL, Babcock WD, Zaroff JG (2007) Donor cardiac troponin I levels do not predict recipient survival after cardiac transplantation. J Heart Lung Transplant 26(10):1048-1053
177. Madan S, Saeed O, Shin J, Sims D, Goldstein D, Pina I, et al. Donor troponin and survival after cardiac transplantation: an analysis of the United Network of Organ Sharing Registry. Circ Heart Fail. 2016;9(6)

178. Schechter MA, Watson MJ, Feger BJ, Southerland KW, Mishra R, Dibernardo LR et al (2016) Elevated cardiac troponin I in preservation solution is associated with primary graft dysfunction. $\mathrm{J}$ Card Fail 22(2):158-162

179. Groenning BA, Raymond I, Hildebrandt PR, Nilsson JC, Baumann M, Pedersen F (2004) Diagnostic and prognostic evaluation of left ventricular systolic heart failure by plasma $\mathrm{N}$ terminal pro-brain natriuretic peptide concentrations in a large sample of the general population. Heart. 90(3):297-303

180. Yamamoto K, Burnett JC Jr, Jougasaki M, Nishimura RA, Bailey KR, Saito Y et al (1996) Superiority of brain natriuretic peptide as a hormonal marker of ventricular systolic and diastolic dysfunction and ventricular hypertrophy. Hypertension (Dallas, Tex : 1979) 28(6):988-994

181. Krittayaphong R, Boonyasirinant T, Saiviroonporn P, Thanapiboonpol P, Nakyen S, Udompunturak S (2008) Correlation between NT-pro BNP levels and left ventricular wall stress, sphericity index and extent of myocardial damage: a magnetic resonance imaging study. J Card Fail 14(8):687-694

182. Giallauria F, Cirillo P, Lucci R, Pacileo M, De Lorenzo A, D'Agostino $\mathrm{M}$ et al (2008) Left ventricular remodelling in patients with moderate systolic dysfunction after myocardial infarction: favourable effects of exercise training and predictive role of $\mathrm{N}$ terminal pro-brain natriuretic peptide. Eur J Cardiovasc Prev Rehabil 15(1):113-118

183. de Lemos JA, Morrow DA (2007) Use of natriuretic peptides in clinical decision-making for patients with non-ST-elevation acute coronary syndromes. Am Heart J 153(4):450-453

184. Dronavalli VB, Ranasinghe AM, Venkateswaran RJ, James SR, McCabe CJ, Wilson IC et al (2010) N-terminal pro-brain-type natriuretic peptide: a biochemical surrogate of cardiac function in the potential heart donor. Eur J Cardiothorac Surg 38(2):181-186

185. Vorlat A, Conraads VM, Jorens PG, Aerts S, Van Gorp S, Vermeulen $T$ et al (2012) Donor B-type natriuretic peptide predicts early cardiac performance after heart transplantation. J heart lung transplant 31(6):579-584

186. Aharinejad S, Andrukhova O, Gmeiner M, Thomas A, Aliabadi A, Zuckermann A et al (2009) Donor serum SMARCAL1 concentrations predict primary graft dysfunction in cardiac transplantation. Circulation. 120(11 Suppl):S198-S205

187. Jiang BH, Rue E, Wang GL, Roe R, Semenza GL (1996) Dimerization, DNA binding, and transactivation properties of hypoxia-inducible factor 1. J Biol Chem 271(30):17771-17778

188. Aharinejad S, Schafer R, Krenn K, Zuckermann A, Schneider B, Neumann F et al (2007) Donor myocardial HIF-1alpha is an independent predictor of cardiac allograft dysfunction: a 7-year prospective, exploratory study. Am J Transplant Off J Am Soc Transplant Am Soc Transplant Surg 7(8):2012-2019

189. Loor G, Schumacker PT (2008) Role of hypoxia-inducible factor in cell survival during myocardial ischemia-reperfusion. Cell Death Differ 15(4):686-690

190. Amaral N, Okonko DO (2015) Mitigation of myocardial ischemia-reperfusion injury via HIF-1alpha-frataxin signaling. Am J Physiol Heart Circ Physiol 309(5):H728-H730

191. Giangreco N, Chen E, Zorn E, Restaino S, Colombo PC, Tatonetti $\mathrm{N}$ et al (2017) Abstract 19311: identification of novel primary graft dysfunction biomarkers using exosome proteomics. Circulation 136(Suppl 1):A19311-A1931A

192. Fine B, Chen E, Lebreton G, Restaino S, Taupin J, Zorn E et al (2018) Pre-transplant serum exosome proteomics differentiates right and left ventricular primary graft dysfunction. J Heart Lung Transplant 37(4):S24 
193. Wagner FM, Subbotina I, Deuse T, Marcsek P, Treede H, Kubik M et al (2013) Additional intraoperative blood cardioplegia to improve donor heart ischemic tolerance - a single center prospective cohort study. Thorac Cardiovasc Surg 61(S 01):OP127

194. Cerny S, Pavel P, Pirk J, Hola I, Brezina A, Sedlacek J et al (2002) Donor myocardial protection using secondary blood cardioplegia during heart transplantation: prospective randomized study in 100 patients. J Heart Lung Transplant 21(1):61-62

195. Morcos K, Singh S, De Das S, AlHaideri H, Hegazy Y, Dalzell J et al (2018) Novel technique to reduce warm ischemic time during cardiac implantation. J Heart Lung Transplant 37(4):S425

196. Habertheuer A, Kocher A, Laufer G, Andreas M, Szeto WY, Petzelbauer P et al (2014) Cardioprotection: a review of current practice in global ischemia and future translational perspective. BioMed Res Int 2014:325725

197. Russ MA, Prondzinsky R, Christoph A, Schlitt A, Buerke U, Soffker G et al (2007) Hemodynamic improvement following levosimendan treatment in patients with acute myocardial infarction and cardiogenic shock. Crit Care Med 35(12):2732-2739

198. Mebazaa A, Nieminen MS, Packer M, Cohen-Solal A, Kleber FX, Pocock SJ et al (2007) Levosimendan vs dobutamine for patients with acute decompensated heart failure: the SURVIVE randomized trial. JAMA. 297(17):1883-1891

199. Weis F, Beiras-Fernandez A, Kaczmarek I, Sodian R, Kur F, Weis $M$ et al (2009) Levosimendan: a new therapeutic option in the treatment of primary graft dysfunction after heart transplantation. J Heart Lung Transplant 28(5):501-504

200. Beiras-Fernandez A, Kur F, Kaczmarek I, Frisch P, Weis M, Reichart B et al (2011) Levosimendan for primary graft failure after heart transplantation: a 3-year follow-up. Transplant Proc 43(6):2260-2262

201. Sundberg S, Antila S, Scheinin H, Hayha M, Virtanen M, Lehtonen L (1998) Integrated pharmacokinetics and pharmacodynamics of the novel calcium sensitizer levosimendan as assessed by systolic time intervals. Int J Clin Pharmacol Ther 36(12):629-635

202. Du Toit EF, Genis A, Opie LH, Pollesello P, Lochner A (2008) A role for the RISK pathway and KATP channels in pre- and postconditioning induced by levosimendan in the isolated guinea pig heart. Br J Pharmacol 154(1):41-50

203. Papp JG, Pollesello P, Varró AF, Végh ÁS (2006) Effect of levosimendan and milrinone on regional myocardial ischemia/ reperfusion-induced arrhythmias in dogs. J Cardiovasc Pharmacol Ther 11(2):129-135

204. Cammarata GAAM, Weil MH, Sun S, Huang L, Fang X, Tang W (2006) Levosimendan improves cardiopulmonary resuscitation and survival by KATPChannel activation. J Am Coll Cardiol 47(5):1083-1085

205. Hönisch A, Theuring N, Ebner B, Wagner C, Strasser RH, Weinbrenner C (2010) Postconditioning with levosimendan reduces the infarct size involving the PI3K pathway and KATPchannel activation but is independent of PDE-III inhibition. Basic Res Cardiol 105(2):155-167

206. Hasslacher J, Bijuklic K, Bertocchi C, Kountchev J, Bellmann R, Dunzendorfer S et al (2011) Levosimendan inhibits release of reactive oxygen species in polymorphonuclear leukocytes in vitro and in patients with acute heart failure and septic shock: a prospective observational study. Critical Care (London, England) 15(4):R166-R

207. Nguyen TC, Kiss JE, Goldman JR, Carcillo JA (2012) The role of plasmapheresis in critical illness. Crit Care Clin 28(3):453-vii

208. Rydberg L (2001) ABO-incompatibility in solid organ transplantation. Transfusion medicine (Oxford, England) 11(4):325-342

209. Wang SS, Chou NK, Ko WJ, Chi NH, Hung SC, Hsu RB et al (2006) Effect of plasmapheresis for acute humoral rejection after heart transplantation. Transplant Proc 38(10):3692-3694

210. Ince V, Aydin C, Otan E, Karabulut K, Koc S, Kayaalp C et al (2013) Comparison of plasmapheresis and molecular adsorbent recirculating system efficacy in graft failure after living donor liver transplantation. Transplant Proc 45(3):971-973

211. Mandal AK, King KE, Humphreys SL, Maley WR, Burdick JF, Klein AS (2000) Plasmapheresis: an effective therapy for primary allograft nonfunction after liver transplantation. Transplantation. 70(1):216-220

212. Chou HW, Chi NH, Lin MH, Chou NK, Tsao CI, Yu HY et al (2012) Steroid pulse therapy combined with plasmapheresis for clinically compromised patients after heart transplantation. Transplant Proc 44(4):900-902

213. Chang DH, Kittleson M, Patel J, Aintablian T, Levine R, Geft D et al (2017) (373) - Treatment of primary graft dysfunction with plasmapheresis improves outcome. J Heart Lung Transplant 36(4, Supplement):S147

Publisher's note Springer Nature remains neutral with regard to jurisdictional claims in published maps and institutional affiliations. 